Borowski Bartosz, Koziol Malgorzata, Markiewicz-Gospodarek Agnieszka. The potential influence of injuries in basketball over the basketball players. Journal of Education, Health and Sport. 2022;12(1):265-273. eISSN 2391-8306. DOI http://dx.doi.org/10.12775/JEHS.2022.12.01.22

https://apcz.umk.pl/JEHS/article/view/JEHS.2022.12.01.022

https://zenodo.org/record/5905288

The journal has had 40 points in Ministry of Education and Science of Poland parametric evaluation. Annex to the announcement of the Minister of Education and Science of December 21, 2021. No. 32343. Has a Journal's Unique Identifier: 201159. Scientific disciplines assigned: Physical Culture Sciences (Field of Medical sciences and health sciences); Health Sciences (Field of Medical Sciences and Health Sciences).

Punkty Ministerialne z 2019 - aktualny rok 40 punktów. Zalącznik do komunikatu Ministra Edukacji i Nauki z dnia 21 grudnia 2021 r. Lp. 32343. Posiada Unikatowy Identyfikator Czasopisma: 201159. Przypisane dyscypliny naukowe:Nauki o kulturze fizycznej (Dziedzina nauk medyczych i nauk o zdrowiu); Nauki o zdrowiu (Dziedzina nauk medycznych i nauk o zdrowiu).

(1) The Authors 2022;

This article is published with open access at Licensee Open Journal Systems of Nicolaus Copernicus University in Torun, Polan

Open Access. This article is distributed under the terms of the Creative Commons Attribution Noncommercial License which permits any noncommercial use, distribution, and reproduction in any medium,

provided the original author (s) and source are credited. This is an open access article licensed under the terms of the Creative Commons Attribution Non commercial license Share alike

The authors declare that there is no conflict of interests regarding the publication of this paper.

Received: 02.01.2022. Revised: 17.01.2022. Accepted: 26.01.2022.

\title{
The potential influence of injuries in basketball over the basketball players
}

\author{
Bartosz Borowski $^{1,2}$, Małgorzata Kozioł ${ }^{3}$, Agnieszka Markiewicz-Gospodarek ${ }^{4}$ \\ 1 Students Scientific Association at the Department of Human Anatomy, Medical University of Lublin, \\ Lublin,Poland \\ ${ }^{2}$ Students Scientific Association at the Chair and Department of Medical Microbiology, Medical University of \\ Lublin, Lublin, Poland \\ ${ }^{3}$ Chair and Department of Medical Microbiology, Medical University of Lublin, Lublin, Poland \\ ${ }^{4}$ Department of Human Anatomy, Medical University of Lublin, Poland
}

Bartosz Borowski ORCID: 0000-0002-1575-4265

Małgorzata M. Kozioł ORCID: 0000-0001-9079-8594

Agnieszka Markiewicz-Gospodarek ORCID: 0000-0002-6266-0261

Address for correspondence:

Department of Human Anatomy, Medical University of Lublin, Poland; Lublin 20-090, ul.Jaczewskiego 4; email: bartosz.borowski@interia.pl

\begin{abstract}
Background: From all the sports around the world, basketball is certainly such popular that it attracts people who loves to watch it, as well as people who loves to play it. Due to the form of this sport, it is very likely to get an injury while playing it.

Aim of the study: The aim of this study was to determine the most repeated types of injuries that might occur to the basketball players, how many basketball players get injured during their professional career, what the convalescence after the injury looked like, and how the COVID-19
\end{abstract}


pandemic influenced the group of professional basketball players of the EBL (Energa Basket Liga), $1 \mathrm{LM}$ and 2LM.

Material and methods: Data collected from a survey sent to 19 basketball players in February 2021.

Results: Most of the basketball players who took part in the examination at some point during their career suffered from an injury, at least one. The part of the body that was affected the most was the lower limb. As the players stated, the injuries that they had were the reason of a long absence in the game. For most of the time the convalescence process consisted of co-operation with the physiotherapist. The mental health of the players was disparately affected by the ensuing injury. As well the COVID-19 pandemic influenced the interviewees' contracts, and most of the times, their mental health's condition. Among the players who were tested positive with the SARS-CoV-2 virus, each one developed some kind of signs of the infection.

Conclusion: Each of the examined players during their professional career at least once suffered form an injury that influenced their physical health, and sometimes also mental health condition. In general, the pandemic period affected badly not only in a sphere of mental health, but also social life elements, such as ability to work out and prepare to the season.

Key words: physical injuries, types of injuries, sport

\section{INTRODUCTION}

Basketball is one of the most popular sports in the world. It also tends to attract more and more spectators over time. The National Basketball Association (NBA), the most popular of all professional basketball leagues in the world, states that, according to Nielsen, this year (2021) second match during the Finals brought about $41 \%$ more viewers than the last year's one. All around the world, millions of people are not only watching basketball on the television, but also play on their own, sometimes amateurishly, and sometimes professionally. The sport itself is quite physically tough. There are few rules, like the 5 seconds rule (a player has 5 seconds to resume the game after losing points or after the touch by passing the ball to another player), 8 seconds rule (team has to walk the ball out of it's half during 8 seconds), or 24 seconds rule (team has 24 seconds to put up a shot), that make basketball a physically-demanding game, as players has to run constantly on the floor, make many jumps, and turns. The sport isn't as contact as, for example, handball, due to strict foul rules, but even though basketball players tend to be tall, muscular men, their body sometimes can't handle the hard physical effort, and they contuse themselves. Usually, the injuries acquired during basketball games aren't life-threating, but there had been some dangerous situations throughout the history of basketball, for example a case of Maurice Stokes, a player who during one of the matches hit his head on the floor, what caused a brain encephalopathy. The aim of this study was to analyze the most repeated types of injuries that might occur to the basketball players, how many basketball players get injured during their professional career, what the convalescence after the injury looked like, and how the COVID-19 pandemic influenced the group of professional basketball players of the EBL (Energa Basket Liga), 1LM and 2LM. We've assumed that most of the examined players have had some injury during their professional career. 


\section{MATERIALS AND METHODS}

A randomized cohort group was made, which consisted of nineteen professional basketball players, aged variously between 18 and 40 years old (eight players were younger than 25 years old, and eleven- older than 25 years old). The main eligibility criterion was performing in three main polish professional basketball leagues: Energa Basket Liga (EBL), 1. Liga Mężczyzn (1LM) and 2. Liga Mężczyzn (2LM). The data was collected by using the authorial survey that was sent online to the players in the beginning of February 2021, and the collection have lasted until the end of February 2021.

\section{RESULTS}

To get the following results we've used mostly Microsoft Excel, and have made basic statistical measures, such as mean and standard deviation calculation. Within the group of nineteen examined basketball players, the majority (about 44\%) has been practicing basketball for ten years. About 39\% has been playing for five years, and only about 16\%- for less than five or more than ten years, with the most experienced player practicing for twelve years.

\section{Types of injury}

The main question of the survey was about having any injury during players' professional career:

- $94,73 \%$ of players stated that they have had some injury at some point of their career.

- $68,42 \%$ of the players have been excluded for playing for a long period of time because of injury.

- Most of the injuries ( $89 \%$ of all) concerned the lower limb. The players complained about an anterior crucial ligament (ACL) rupture, a collateral ligament desmectasis or strain, and a lateral meniscus injury (concerning a knee joint), an ankle ligaments strain or rupture, twisting an ankle joint, a bone break (e.g., a tibia break), metatarsal bones or fibula breaks.

- The other types of injuries were marked: two injuries concerned the back and the shoulder girdle/upper limb: one back injury which turned out to be a spinal disc herniation, and one upper limb injury, which was a humerus break.

- $78,94 \%$ of players needed a medical treatment of the injury.

\section{Treatment of the injury}

The most common type of treatment included physiatrics, also 31,57\% (six people) of players needed a surgical treatment of their trauma. Only 15,78\% (three people) used a pharmacological treatment. As for a convalescence period, it usually lasted more than a month, sometimes more than a week and less than a month, but $10,52 \%$ (two people) of the players needed more than a year to regain health.

\section{Break and mental health}

For some of the players, the physical injury also influenced their mental health. About $66 \%$ of the players claim that their injury has not changed anything in their mental health sphere, but the rest of the players states otherwise. For every player but one, the injury didn't cause any sleep disorder or social withdrawal. Their mental health during the convalescence process extended from "very good" to "correct", and no player claimed that their mental state was "bad" or "very bad".

The COVID-19 pandemic has made a various impact on the players' contract, as some of the players stated that their contract has been resolved immediately (10,52\%; two players), it lasted until 
the designated time and then has been resolved (26,31\%; five players), the salary has been lowered (31,57\%; six players) or it hasn't made any impact on the contract (also $31,57 \%$; six players). Ten out of total nineteen examined players $(52,63 \%)$ felt unsecure about their source of income and material standing. The periodic closure of the sport facilities, like gyms or swimming pools, has been noticeable for almost $75 \%$ of the players, as they state that there have been such problems as inability to workout or prepare to the season, the physical activity and thus muscle mass decrease, or a decline in the comfort of working. Those problems have led the players to work out at home, what has been a way of training for about $90 \%$ of the players. During the COVID-19 pandemic 57,89\% (eleven out of nineteen players) has been feeling anxiety, fear, or inner pressure, mostly in moderate or low level.

Also 57,89\% (eleven players) has been tested positive for SARS-CoV-2 virus (nine of them took a PCR test, six- checked their antibodies level in blood). The most noticeable signs of the infection, and the most frightening ones, were a loss of smell, then osteoarticular and muscular aches. For most of the players, the loss of smell lasted for 2 weeks or less, but two of the infected players has not regained it yet. The isolation that was necessary for the infected players caused a low activity and a low self-esteem for the two of them.

\section{DISCUSSION}

Basketball due to its intensity relates with many different types of injuries, which sometimes need an advanced treatment method to be dealt with. Professional basketball players tend to be injured at least once during their career. The analysis of the collected data shows that almost all of the respondents $(94,7 \%)$ had already been injured. $78,94 \%$ of injured players stated that they needed a medical treatment of the injury. As well the studies of Drakos et al. confirms that basketball is related to the high rate of injuries, and they have noted that within the population of 1094 basketball players (which entered the database throughout 3,3 $\pm 2,6$ seasons, so the total amount of entries into the database was 6145), there were 12594 injuries in total. Most of the injuries concerned the lower extremity of the body (7853 injuries) [1]. During the whole players' career, which can last for many years, the risk of getting an injury is therefore high, even though the rules of the game has changed throughout the years and made the basketball less aggressive.

According to the literature, injuries are very common in the basketball, and especially the ones concerning the lower limb. Those injuries concerned many different structures, such as bones, joints, tendons, and ligaments. Quick running, changing position very fast and jumping can easily lead to the injury [2]. A part of the lower limb that seems to be injured most often is the ankle joint, and the studies of Tummala et al. confirms it. The scientists noted that ankle injuries are the most common of all the types of injuries at any level of competition, with the ankle ligament sprain representing $22,6 \%$ of all basketball injuries in collegiate level of competition [3]. Our results shows that $35,3 \%$ of the respondents' injuries concerned the ankle joint. The other sources also state that about $45 \%$ of the ankle injuries were caused during the player's landing on the floor. [4] 
Knee joint is also the part that can suffer during the play. According to Hutchison et al. studies, $33,7 \%$ (32 out of 95) collegiate basketball players presented ultrasonographic evidence of patellar tendon abnormality, and $21 \%$ (20 of the examined players) had been diagnosed with patellar tendinopathy, which is a degenerative disease that affects e.g. basketball and volleyball players [5]. In our study, knee injuries were $29,4 \%$ of all injuries.

The less frequent type of the injury in basketball is the back injury, but even though they are not that common as the lower extremity injuries, they tend to happen, and many basketball players complain about the lower back pain. The study of Hagiwara et al. shows that 12,9\% (76 out of total 590) examined basketball players suffered from lower back pain. The scientists also state that the lower back pain is very often associated with shoulder or elbow pain or anomalies, not only within basketball players, but also diver, tennis players or cricket players. The cause of the lower back pain in basketball is mostly the number of quick movements that require lower back mobility. It can cause microdamage of the latissimus dorsi muscle, which covers the back, and it is also used during shoulder movements [6]. Our study, even though it had a small group of examined players, noted one back injury, which was spinal disc herniation.

The shoulder girdle injury affected one of the players, but it turned out to be a humerus break, so it was in fact an upper limb trauma. According to some studies, upper limb can be often injured in so called "overhead sports", which are the sports that often require high range shoulder movements, sometimes on the edge of the range of motion. For example, $12 \%$ to $19 \%$ of all the injuries in baseball are located in the shoulder area. [7] About head trauma our study has not found any within the examined population of basketball players, but sometimes an injury of the head area can also occur. According to some data, they make up $7-21 \%$ of all the injuries in basketball [8]. The body part classification can be difficult in those types of traumas, for example if the break concerned a tubercle of humerus, which is located near the upper extremity.

Every injury, in all sports, require the medical attention, so it can be diagnosed properly. Undiagnosed trauma can lead to further problems and can become more severe issue. Professional players almost every time have the right medical care provided and can use the consultation with a doctor or a physiotherapist. Various injuries which can happen in the basketball may require different treatment. Many studies provide information of the types of treatment that needs to be applied to different injuries. For example, about $60-70 \%$ of acute ankle sprains doesn't require surgical treatment [9], while only about $19 \%$ of the players that didn't undergo the surgery after the ACLR (anterior cruciate ligament rupture) return to their preinjury fitness [10]. Nowadays, most of the injuries can be healed by surgical treatment, as well as conservative treatment. The decision of undergoing a surgery most often depends on the level of the injury. For example, ankle sprains can be divided into grades, and the I and II grade sprains don't require surgical attention, while the higher grades often do [11]. Sometimes, the treatment begins with conservative care, such as RICE therapy (rest, ice, compress, 
elevate), and if it fails to help, the surgical treatment is required. This can happen e.g., in the healing process of Achilles tendinopathy, where surgical help is required in $25-33 \%$ of the cases [12]. Our studies indicates that $37,5 \%$ of the injuries within the tested population of players required surgical treatment.

The basketball players co-operate with many professionals, such as the physiotherapists, the physical preparation coaches, and the medical staff to prevent injuring themselves and get the right physical condition throughout the season. As much as $75 \%$ of the injuries within the tested population required physiotherapist's help. The key to avoid the injury is the right physical preparation before the season and each game. The pre-match warm up is crucial to the injury prevention, and, according to many studies, can reduce the risk of getting an injury [13]. The convalescence period can last days, weeks or even months, it all depends of the grievousness of the injury.

In many cases, the physical injury also causes mental health anomaly. Many players fear if they will be able to return to their pre-injury fitness after the convalescence process. Some studies that were conducted on the athletes that suffered from the sport-related concussion reveal that sometimes athletes developed depression or anxiety after the trauma [14]. The depression within athletes is mostly associated with injuries, and the former athletes that had been injured several times during their career, or underwent surgical treatment, were more likely depressed, as some studies state [15]. However, the studies of Pluhar et al. show that people who do sport have lower anxiety or depression proportion (8\%) than the general population $(11,3 \%)$ [16]. In our study, 33,3\% of the injured players state that the injury has made an impact on their mental health condition. The study of Jonge et al. shows that the mental health is crucial in the recovery time after the injury, as the healthy passion for the sport helps to overcome the injury, while the obsessive passion can only worsen the injury [17]. The examined basketball players stated that their mental health condition during the convalescence period was rather good.

In the year 2020 the world got overwhelmed by the COVID-19 pandemic, caused by the SarsCoV-2 virus. Many aspects of life, such as working, exercising, and spending free time got overmarked by the restrictions. The pandemic also influenced over basketball players. The physical preparation was very constricted for the examined players, because of the pandemic-related temporary closure of the sport facilities, and most of the examined players states that it was hard for them to get the right fitness for the regular season. The restrictions mentioned earlier also affected the basketball players, as they had to learn to decrease the risk of COVID-19 transmission to minimum, by such rules as not touching their face, sterilizing their equipment, or avoiding unnecessary contact with other players. Some studies state that the lay-off period caused by the lockdown could decrease the physical preparation of the players so much, that after coming back to professional trainings they must not train on the same level of intensity as before the lockdown [18]. The other sports were also affected by the COVID-19 pandemic. For example, the studies of Radzimiński et al. compared the physical preparation for the regular season in two professional football leagues in Europe: German Bundesliga 
and Polish Ekstraklasa. The total distance covered by the players in Bundesliga before the COVID-19 pandemic hasn't changed much after the lockdown, while in the Polish Ekstraklasa it decreased significantly in the post-pandemic period [19]. As well as any other illness of injury, COVID-19 affects not only the physical health, but also mental health. Most of the examined basketball players state that the COVID-19 pandemic had an influence over their mental health condition. The studies of Sun et al. also indicate that the pandemic made an impact over the mental health, especially the depression and anxiety level [20].

\section{CONCLUSIONS}

Many basketball players at some point during their professional career gets injured. Most of the injuries concern the lower extremity of the body, usually the ankle joint or the knee joint. The physical injury can affect variously the player's mental health, leading to such conditions as anxiety or even depression. The convalescence period after getting injured can last differently and can except the player from the game for days or months. It most often concentrates on the co-operation with the physiotherapists, but sometimes, if the injury is serious, the surgical treatment is necessary. The COVID-19 pandemic caused lack of the physical preparation to the season, and often influenced the players' mental health condition. We are aware that the results of our study are limited by the low number of the examined players, but the obtained data indicates that there is a possibility to conduct further studies about the injuries that occur in basketball.

\section{REFERENCES}

[1] Drakos M C, Domb B, Starkey C, Callahan L, Allen A A. Injury in the national basketball association: a 17-year overview. Sports health, 2(4), 284-290. https://doi.org/10.1177/1941738109357303

[2] Andreoli C V, Chiaramonti B C, Buriel E, Pochini A C, Ejnisman B, Cohen M. Epidemiology of sports injuries in basketball: integrative systematic review. BMJ open sport \& exercise medicine, 4(1), e000468. https://doi.org/10.1136/bmjsem-2018-000468

[3] Tummala S V, Hartigan D E, Makovicka J L, Patel K A, Chhabra A. 10-Year Epidemiology of Ankle Injuries in Men's and Women's Collegiate Basketball. Orthopaedic journal of sports medicine, 6(11), 2325967118805400. https://doi.org/10.1177/2325967118805400

[4] McKay G D, Goldie P A, Payne W R, Oakes B W. Ankle injuries in basketball: injury rate and risk factors. British journal of sports medicine, 35(2), 103-108. https://doi.org/10.1136/bjsm.35.2.103

[5] Hutchison M K, Houck J, Cuddeford T, Dorociak R, Brumitt J. Prevalence of Patellar Tendinopathy and Patellar Tendon Abnormality in Male Collegiate Basketball Players: A CrossSectional Study. Journal of athletic training, 54(9), 953-958. https://doi.org/10.4085/1062-6050-70-18 
[6] Hagiwara Y, Yabe Y, Sekiguchi T, Momma H, Tsuchiya M, Kanazawa K, et al. Upper Extremity Pain Is Associated with Lower Back Pain among Young Basketball Players: A Cross-Sectional Study. The Tohoku journal of experimental medicine, 250(2), 79-85. https://doi.org/10.1620/tjem.250.79

[7] Tooth C, Gofflot A, Schwartz C, Croisier J L, Beaudart C, Bruyère O, et al. Risk Factors of Overuse Shoulder Injuries in Overhead Athletes: A Systematic Review. Sports health, 12(5), 478-487. https://doi.org/10.1177/1941738120931764

[8] Harmer P A. Basketball injuries. Medicine and sport science, 49, 31-61. https://doi.org/10.1159/000085341

[9] Halabchi F, Hassabi M. Acute ankle sprain in athletes: Clinical aspects and algorithmic approach. World journal of orthopedics, 11(12), 534-558. https://doi.org/10.5312/wjo.v11.i12.534

[10] Krause M, Freudenthaler F, Frosch K H, Achtnich A, Petersen W, Akoto R. Operative Versus Conservative Treatment of Anterior Cruciate Ligament Rupture. Deutsches Arzteblatt international, 115(51-52), 855-862. https://doi.org/10.3238/arztebl.2018.0855

[11] Vasta S, Papalia R, Albo E, Maffulli N, Denaro V. Top orthopedic sports medicine procedures. Journal of orthopaedic surgery and research, 13(1), 190. https://doi.org/10.1186/s13018018-0889-8

[12] Aicale R, Tarantino D, Maffulli N. Overuse injuries in sport: a comprehensive overview. Journal of orthopaedic surgery and research, 13(1), 309. https://doi.org/10.1186/s13018-018-1017-5

[13] Herman K, Barton C, Malliaras P, Morrissey D. The effectiveness of neuromuscular warm-up strategies, that require no additional equipment, for preventing lower limb injuries during sports participation: a systematic review. BMC medicine, 10, 75. https://doi.org/10.1186/1741-7015-10-75

[14] Rice S M, Parker A G, Rosenbaum S, Bailey A, Mawren D, Purcell R. Sport-Related Concussion and Mental Health Outcomes in Elite Athletes: A Systematic Review. Sports medicine (Auckland, N.Z.), 48(2), 447-465. https://doi.org/10.1007/s40279-017-0810-3

[15] Souter G, Lewis R, Serrant L. Men, Mental Health and Elite Sport: a Narrative Review. Sports medicine - open, 4(1), 57. https://doi.org/10.1186/s40798-018-0175-7

[16] Pluhar E, McCracken C, Griffith K L, Christino M A, Sugimoto D, Meehan W P 3rd. Team Sport Athletes May Be Less Likely To Suffer Anxiety or Depression than Individual Sport Athletes. Journal of sports science \& medicine, 18(3), 490-496.

[17] de Jonge J, Balk Y A, Taris T W. Mental Recovery and Running-Related Injuries in Recreational Runners: The Moderating Role of Passion for Running. International journal of environmental research and public health, 17(3), 1044. https://doi.org/10.3390/ijerph17031044

[18] Bourdas D I, Zacharakis E D, Travlos A K, Souglis A. Return to Basketball Play Following COVID-19 Lockdown. Sports (Basel, Switzerland), 9(6), 81. https://doi.org/10.3390/sports9060081

[19] Radzimiński Ł, Padrón-Cabo A, Konefał M, Chmura P, Szwarc A, Jastrzębski Z. The Influence of COVID-19 Pandemic Lockdown on the Physical Performance of Professional Soccer Players: An 
Example of German and Polish Leagues. International Journal of Environmental Research and Public Health. 2021; 18(16):8796. https://doi.org/10.3390/ijerph18168796

[20] Sun S, Zhang S X, Jahanshahi A A, Jahanshahi M. Drilling under the COVID-19 pandemic: A diary study of professional football players' mental health and workout performance. Stress and health : journal of the International Society for the Investigation of Stress, 10.1002/smi.3059. Advance online publication. https://doi.org/10.1002/smi.3059 